\title{
Relational Coordination as an Indicator of Teamwork Quality: Potential Application to the Success of e-Learning at Universities
}

\author{
http://dx.doi.org/10.3991/ijet.v10i2.4102 \\ C. De Pablos Heredero ${ }^{1}$, S. Haider ${ }^{2}$ and A. García Martínez ${ }^{3}$ \\ ${ }^{1}$ Universidad Rey Juan Carlos, Madrid, Spain \\ ${ }^{2}$ COMSATS Institute of Information Technology, Vehari, Pakistan \\ ${ }^{3}$ Universidad de Córdoba, Córdoba, Spain
}

\begin{abstract}
Teamwork has emerged as a contemporary management technique; so much so that the failure to adopt teamwork strategies is often considered an important cause of failure when attempting to implement changes within organizations. Studying teamwork in relation to the implementation of organizational routines to improve results in online Educational Systems is important because many proposals for improving e-learning systems cannot be effectively implemented without collaborative teamwork. In this work, the relational coordination model is applied to measure teamwork to a representative sample of lecturers and students that teach on e-learning-based systems in Spain and the results are presented. Given the importance of interaction among educational professionals, the model of relational coordination is well positioned to address the quality of teamwork in university contexts. However, to these researchers' knowledge, this is the first research to apply the relational coordination model in the context of organizational routines implemented in e-learning processes.
\end{abstract}

Index Terms - on line educational systems, organizational routines, relational coordination, teamwork.

\section{INTRODUCTION}

Empirical research suggests that organizational routines have a substantial effect on final results of e-learning activities. However, the implementation of organizational routines does not take place in a vacuum. E-learning professionals from different specialties participate in a complex, multidisciplinary, and time-sensitive educational process which requires collaborative teamwork among the various participants [1].

E-learning literature highlights the need for collaborative teamwork to achieve the best results in the teaching and learning process. Although the importance of organizational routines and collaborative teamwork has been well recognized in the e-education literature, little attention has been given to the relationship between these two factors. The present research examines this relationship by applying the relational coordination model [2], [3] to measure the quality of teamwork so that the results can be applied to obtain greater success in e-learning contexts.

"Relational coordination is a mutually reinforcing process of interaction between communication and relationships carried out for the purpose of task integration" [3], pp 301. Shared knowledge, shared goals and mutual respect are the relational dimensions, while frequent, timely, accurate, and problem-solving communications are the communication dimensions of relational coordination. Figure 1 shows the relational and communication dimensions of relational coordination and shows the interaction between them.

In order to conceptualize the quality of teamwork as the relational coordination among team members, this paper takes insights from [3] and [5]. [3] was of the view that "If groups are sets of organizational members who must work interdependently to achieve a task designated by the organization, and coordination is the management of interdependence, then coordination is arguably a central element of what effective groups do." As teamwork is the ability of a group of people to work together, it can be argued that groups working on interdependent activities are, in fact, involved in teamwork. If coordination is what the groups do and teamwork is also what the groups do, then teamwork will be reflected by the coordination in a team. According to Gittell's distinct point of view, relational coordination refers to the interactions among participants [3], p. 1410. As the quality of teamwork has also been called the quality of interactions in teams [5], p. 436, it is argued that the level of relational coordination among the members involved in the reperfusion process reflects the quality of their teamwork.

More specifically, according to [3] point of view, "the process of interactions among [group or team] participants has been recognized as a more spontaneous form of coordination-also referred as 'teamwork' and can be conceived as relational coordination (p.1410). From our point of view, the coincidence of [3] and [5] on the interactions among participants (i.e. some research considers the quality of interactions as teamwork quality [5], while others consider the quality of interactions as relational coordination [3]) affirms that relational coordination manifests the quality of teamwork within teams. In this sense, teamwork quality is a multidimensional construct represented by a continuum of willingness and commitment of team members to share collective goals [6] and knowledge [7], have a mutual respect for other team members [8], [2], [3], [4], and communicate effectively [8]. These explanations suggest that relational coordination is well positioned to explain the quality of teamwork.

The following section discusses the relationship between each individual dimension of relational coordination and the implementation of organizational routines is discussed. 


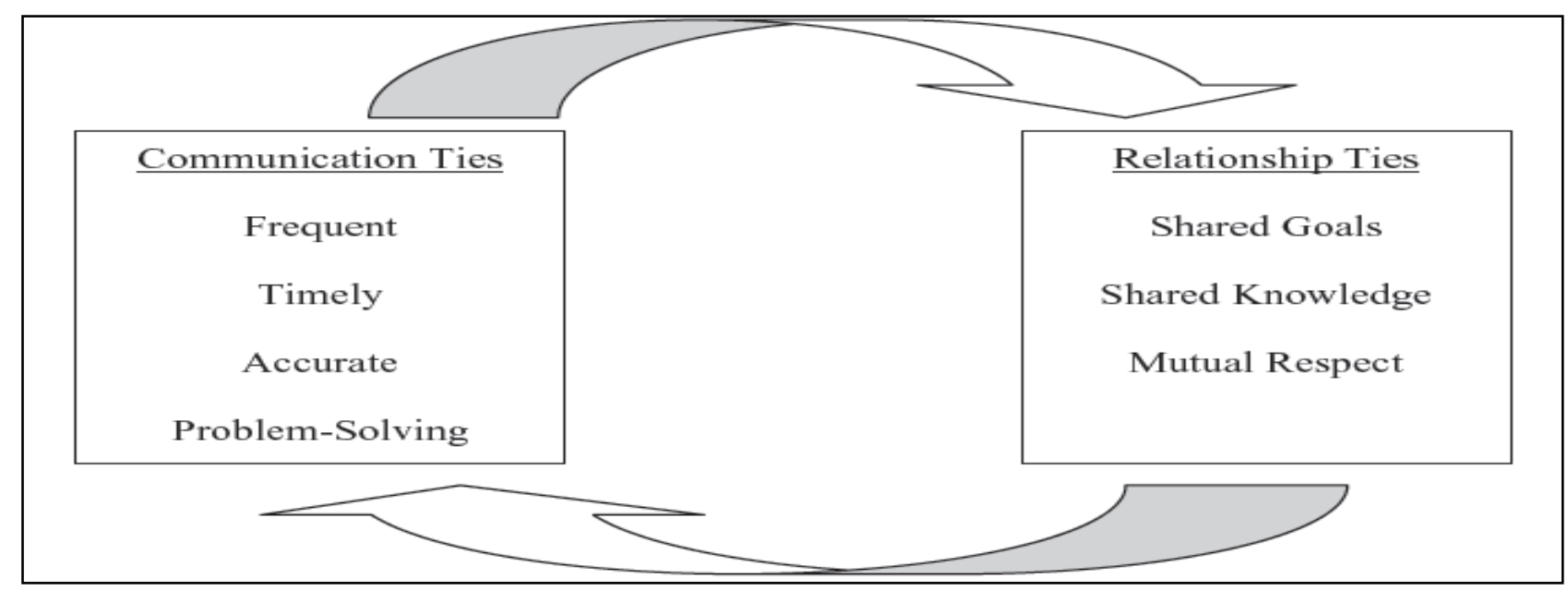

Figure 1. Dimensions of relational coordination [4]

\section{RELATIONSHIP DIMENSIONS}

\section{A. Shared knowledge}

The quality of teamwork is indicated by the presence of an attitude towards exchanging ideas and knowledge among the participants [6]. The authors of [2] and [3] discuss how relational coordination posits that the participants involved in a process need to know how their tasks fit together with the tasks of others so that the impact of one's action on the others' actions can be determined. Gittell's idea coincides with [9] 'team knowledge' in which task domains are translated into a shared mental model, where the procedures are conceptualized as a shared understanding [5], and where there exists a specific knowledge about the task- related behaviors of the other team members [10]. A common understanding among team members about how to execute the next task in an interrelated work process and recognize process-related disruptions [6] is an important determinant of teamwork quality [5], [6].

Knowledge sharing has gained attention in e-learning literature after a recent shift away from individual behavior change theories [11], along with increasing attention towards organizational-level intervention [12]. Knowledge management [13] and organizational learning [14] theories are gaining ground insofar as empirical research in elearning contexts is concerned. The personal knowledge approach to knowledge management recommends that for organizational learning to flourish, individuals should be encouraged to share knowledge.

It is generally maintained that knowledge in education is characterized by the proliferation of information, fragmentation, distribution, and a high degree of context dependency. There is a significant degree of complexity related to managing healthcare knowledge, especially when care providers face uncertainty, rapid change and time constraints [15], [3], [16]. The need to apply specialized skills and knowledge in a timely manner [16], p. 1156 requires organizations to develop a knowledge- sharing climate [7].

The notion of knowledge sharing has gained importance in education literature under the umbrella of 'communities of practice'. The concept of communities of practice $(\mathrm{CoP})$ was originally introduced in education and management literature. Using a knowledge management perspective to improve the implementation of organizational routines [17] emphasizes the development of a collaborative culture of knowledge sharing to improve the implementation of these routines.

These ideas can be extended to the implementation of evidence-based practices/strategies to reduce door to balloon time.

In e-learning contexts, knowledge sharing is important among the participants involved in the process, and involves more than just communicating.

\section{B. Shared goals}

The importance of sharing a goal (or goal sharing) to achieve the best results in e-learning literature has long been discussed. Goal sharing refers to the members' priority to team's common task [18], [19] over other obligations [5]. In the absence of such priorities, negative outcomes are expected from a work process as the participants tend to pursue their individual functional goals without taking into account the super-ordinate goal of the whole process [20]. Collaborative approaches in elearning environments emphasize sharing responsibility and building a consensus among team members towards achieving a common goal [21], [22]. Working together toward a prioritized common goal reflects the team members' shared vision which has been considered necessary for 'effective multi-professional teamwork' [23]. Although teamwork is a necessary process for achieving a common goal, the existence of cognitions, attitudes and behaviors in team members toward a shared effort for a collective team goal is important for teamwork quality [6]. Goal sharing, as an indicator of teamwork quality, provides the basis for effective relationships in organizations. Building such relations positively affects the implementation of plans [24].

Moreover, effective implementation of organizational routines depends on all involved members sharing the same goal. From the perspective of organizational culture, organizations with a culture of sharing common values and goals are most likely to succeed in their implementation efforts [25]. The PRISM model (A Practical, Robust Implementation and Sustainability Model), developed by [26] recognizes organizational culture with shared goals as an important organizational characteristic for the implementation of evidence-based practices. 
PAPER

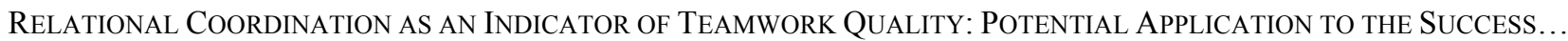

\section{Mutual respect}

In order to achieve a better quality of teamwork, team members working to achieve a common goal should have mutual respect for each other [5]. More precisely, the members working on a same work process should display respect for other participants' work [27], take into account others' ideas, display a contributive behavior [5], and value the contributions of others [3].

Mutual respect is especially important for a work process in which many professionals with highly specialized skills, where different occupational identities and status are involved [27]. Mutual respect in this case is important because the differences in status and occupational identities serve as a source of pride, as well as a source of invidious comparison [27]. People working on e-learning programs have different status and occupational identities. However, everyone's work is important to achieve good results. The existence of distinct occupational identities creates a potential for divisive relationships, and can hamper the coordination process if disrespect occurs.

Implementation of organizational routines requires collaborative relationships among all involved parties [28]. [8] State that collaborative relationships, among other factors, depend on mutual respect. People working on a process of implementing organizational routines require positive interactions for success. However, such interactions require a sense of mutual respect [29]. In an ethnographic study on the dynamics of interactions between organizational routines developers and trainers, as well as organizations and providers that deliver them, [29] identified mutual respect among participants as a primary factor required for the successful implementation of the most efficient model. Therefore, building a culture of mutual respect is an important facilitator needed to implement result-oriented organizational routines.

\section{COMMUNICATION DIMENSIONS}

Communication is seen as an important means of information exchange [30]. The Information Engineering approach conceptualizes communication as a linear transmission of information within an already established social context. The social construction approach to communication posits that communication has the ability not only to transmit information but also to create the dynamic context in which people work [31]. [32] describes that "communication is not just a tool that groups use; groups are best regarded as a phenomenon that emerges from communication". Thus, being an important means of information exchange [30], communication is considered to be an important component of teamwork quality [5]. In other words, the quality of communication in teams indicates the quality of teamwork among participants. The quality of communication, as addressed by [3], is the frequency, timeliness, accuracy, and problem-solving nature of communication.

\section{A. Frequent communication}

Frequent communication refers to the extensiveness of the communication among the members of a team [5]. Frequent communication develops familiarity and helps build relationships among the team members. This extensive type of communication enhances the quality of teamwork through its ability to respond rapidly to new information by minimizing delays [3], [33].

\section{B. Timely communication}

A lack of timeliness often indicates a poor quality of communication [27]. Along with other established objectives like cost and quality, achieving the time objective is fundamental to team performance [34]. E-learning processes that involve strict time constraints require quick and effective responses [16], and are less likely to meet time constraints if there is a lack timely communication among the participants involved. The extent to which the team members are able to communicate in a timely fashion often reflects the quality of teamwork. It implies that in order to implement well-designed e-learning processes, organizational change are required to meet the challenge of improving information exchange in order to establishing effective and timely communication among the different e-learning actors.

\section{Accurate communication}

E-learning organizations often function within high velocity environments that need to operate error free [16]. A rapid response to a training problem based on inaccurate information can result in negative outcomes. As a result, a focus on communication accuracy is essential to reduce the occurrence of potential errors [3]. The importance of accurate communication to insure for group effectiveness is presented in [35], which implies that accurate communication is an important component of teamwork quality. Theoretical models developed to predict the successful implementation of organizational routines have highlighted the importance of accurate communication.

\section{Problem solving communication}

Work processes that involve interdependent activities require joint problem solving strategies [3]. Problem solving requires team members to interact positively to achieve quality teamwork through problem solving communication [36], [35], [3]. Problem solving communication can be considered as an important indicator of teamwork quality because it avoids the negative cycle of blaming and information hiding, keeping the focus instead on continuous improvement and learning [4], p. 155. A noblame culture and open communications are considered important components of positive interpersonal relationships and quality communication, which are important components of teamwork quality [5]. Therefore, problem solving is an effective interpersonal skill for effective teamwork [37], [38].

The implementation process is composed of a set of generic activities that occur across an entire problemsolving sequence [39], p. 320. [40] describes that problem solving in total quality management (TQM)/ continuous quality improvement (CQI) implementation usually consists of teamwork to identify the problem, generate ideas for solutions, evaluate alternatives, and reach consensus decision making (p. 3). Using the same sense to implement organizational routines, these issues need to be communicated among the participants involved in implementation processes. [41] states that developing problem solving competences in professionals is important to implement an evidence-based practice model. [42] also suggests that implementation needs frequent problem-solving.

Based on existing literature, the following tables I and II summarize the dimensions of relational coordination as an indicator of teamwork quality and the effect of relational coordination on the implementation of organizational routines. 
TABLE I.

RELATIONAL COORDINATION AS AN INDICATOR OF TEAMWORK QUALITY

\begin{tabular}{|l|l|}
\hline Shared knowledge & $\begin{array}{l}\text { Cook et al., 2000; Hoegl and Gemuenden, 2001; Sapsed et al., 2002; Hoegl et al., 2003; Faraj and Xiao, 2006; } \\
\text { Radaelli et al.2011 }\end{array}$ \\
\hline Shared goals & $\begin{array}{l}\text { Hackman, 1987; Campion et al., 1993; Bradley et al., 2001; Hoegl and Gemuenden, 2001 Bradley et al., 2006; } \\
\text { Curry et al., 2011 }\end{array}$ \\
\hline Mutual respect & Seaburn et al., 1996; Hoegl and Gemuenden, 2001; Palinkas et al., 2009 \\
\hline Frequent communication & Hoegl and Gemuenden, 2001 \\
\hline Timely communication & Schrader and Goepfert, 1996; Gemuenden and Lechler, 1997 \\
\hline Accurate communication & O'Reilly et al., 1977 Faraj and Xiao, 2006 \\
\hline Problem solving communication & $\begin{array}{l}\text { Rubinstein 2000, Stevenson and Gilly, 1993 Bradley 2006a; Hoegl and Gemuenden, 2001 Stevens and Campion, } \\
1999 ; \text { Jackson et al., 2006 }\end{array}$ \\
\hline
\end{tabular}

TABLE II.

THE EFFECT OF RELATIONAL COORDINATION ON THE IMPLEMENTATION OF ORGANIZATIONAL ROUTINES

\begin{tabular}{|l|l|}
\hline Shared knowledge & Sandars and Heller, 2006; Barwick et al., 2009; Mendel et al. 2008 \\
\hline Shared goals & Wright, 2001Nah and Leu, 2001; Felstein and Glasgow, 2008 \\
\hline Mutual respect & Friedman and Drews, 2005; Brown et al., 2008; Palinkas et al. 2009 \\
\hline Frequent communication & Hoegl and Gemuenden, 2001; Balas et al., 2012 \\
\hline Timely communication & Faraj and Xiao, 2006; Williams et al., 1999 \\
\hline Accurate communication & Lekan et al., 2010 \\
\hline Problem solving communication & Bryson and Bromiley, 1993; Huq and Martin, 2000 Sanares and Heliker, 2002; Metz et al., 2007 \\
\hline
\end{tabular}

\section{REFERENCES}

[1] C. De Pablos Heredero, A. García Martínez, J.M. Perea Muñoz, "The importance of coordination of quality at Universities: an intercontinental comparison in Science Faculties". Communication presented at the International Conference of the Latino-American Association of Technology 2013, ALTEC 2013, Porto, October.

[2] J.H. Gittell, K. Fairfield, B. Bierbaum, W. Head, R. Jackson, M. Kelly, R. Laskin, S. Lipson, J. Siliski, T. Thornhill, J. Zuckerman, "Impact of relational coordination on quality of care, postoperative pain and functioning, and the length of stay: A nine hospital study of surgical patients", Medical Care, vol. 38, n. 8, 2000, pp. 807819. http://dx.doi.org/10.1097/00005650-200008000-00005

[3] J.H. Gittell, "Coordinating mechanisms in care provider groups: Relational coordination as a mediator and input uncertainty as a moderator of performance effects. Management Sci. vol. 48, 2002, pp. 1408-1426. http://dx.doi.org/10.1287/mnsc.48.11.1408.268

[4] J.H. Gittell, D. Weinberg, S. Pfefferle, C. Bishop, "Impact of relational coordination on job satisfaction and quality of care: A study of nursing homes", Human Resource Management Journal, vol. 18, n. 2, 2008, pp.154-170. http://dx.doi.org/10.1111/j.17488583.2007.00063.x

[5] M. Hoegl, H.G. Gemuenden, "Teamwork quality and the success of innovative projects: a theoretical concept and empirical evidence”, Organization Science, vol. 12, n. 4, 2001, pp. 435-449. http://dx.doi.org/10.1287/orsc.12.4.435.10635

[6] M. Hoegl, K.P. Parboteeah, and H.G. Gemuenden "When teamwork really matters: task innovativeness as a moderator of the teamwork-performance relationship in software development projects", Journal Engineering and Technology Management, vol. 20, 2003, pp. 281-302. http://dx.doi.org/10.1016/j.jengtecman.2003.08.001

[7] G. Radaelli, M. Mura, and N. Spiller "Intellectual capital and knowledge sharing: the mediating role of organizational knowledge-sharing climate", Knowledge Management Research \& Practice, vol. 4, 2011, pp.342-352. http://dx.doi.org/10.1057/kmrp.2011.29

[8] D.B. Seaburn, A.D. Lorenz, W.B. Jr. Gunn, B.A. Gawinski, and L.B. Mauksch, Models of Collaboration, New York: Basic Books, 1996.

[9] N.J. Cooke, E. Salas, J.A. Cannon-Bowers, and R.J. Stout, "Measuring Team Knowledge", Human Factors, vol, 42, 2000, pp. 145151. http://dx.doi.org/10.1518/001872000779656561
[10] J. Sapsed, J. Bessant, D. Partington, D. Tranfield, and M. Young, "Teamworking and Knowledge Management: A Review of Converging Themes", International Journal of Management Reviews, vol. 4, n. 1, 2002, pp. 71-85.

[11] G. Godin, A. Belanger-Gravel, M. Eccles, and J. Grimshaw, "Healthcare professionals' intentions and behaviours: a systematic review of studies based on social cognitive theories", Implement Science, vol. 3, 2008, p.36.

[12] C. De Pablos Heredero' E. Diaz OCampo, J.M. Perea Muñoz, A.García Martínez, "The influence of relational coordination in the position of universities in the quality rankings at Ecuador", Inted Conference, Valencia, March, 2014.

[13] I. Nonaka, "The knowledge creating company", Harvard Business Review, vol. 69 (6 Nov-Dec), 1991, pp. 96-104.

[14] C. Argyris, D.A. Schön, Organizational Learning, AddisonWesley, Reading, 1978.

[15] S. Faraj, L. Sproull, "Coordinating expertise in software development teams". Management Sci,. vol. 46, n. 12, 2000, pp. 1554 1568. http://dx.doi.org/10.1287/mnsc.46.12.1554.12072

[16] S. Faraj, Y. Xiao, "Coordination in fast response organizations", Management Science, vol. 52, n. 8, 2006, pp. 1155-1169. http://dx.doi.org/10.1287/mnsc. 1060.0526

[17] J. Sandars, R. Heller, "Improving the implementation of evidencebased practice: a knowledge management perspective", Journal of Evaluation in Clinical Practice, vol. 12, n. 3, 2006, pp. 341-346. http://dx.doi.org/10.1111/j.1365-2753.2006.00534.x

[18] J.R. Hackman, "The design of work teams". J. W. Lorsch, ed. Handbook of Organizational Behavior. Prentice-Hall, Englewood Cliffs, NJ, 1987, pp. 67-102.

[19] M.A. Campion, G.J. Medsker, and A.C. Higgs "Relations between work group characteristics and effectiveness: Implications for designing effective work groups", Personnel Psych. vol. 46, n. 4, 1993, pp. 823-850. http://dx.doi.org/10.1111/j.17446570.1993.tb01571.x

[20] J.G. March, H.A. Simon H.A, Organizations, New York: Wiley, 1958.

[21] M. D. Mailick, A.A. Ashley, "Politics of interprofessional collaboration: Challenge to advocacy", Social Casework, vol. 62, 1981, pp. 131-137. 
[22] L.L. Ellingson, "Communication, Collaboration, and Teamwork among Health Care Professionals", A Quarterly Review of Communication Research, vol. 21, n. 3, 2002, pp. 1-43.

[23] M. Freeman, C. Miller, and N. Ross,'The impact of individual philosophies of teamwork on multi-professional practice and the implications for education", Journal of Interprofessional Care, $\begin{array}{llll}\text { vol. } 14, \quad \text { n. } 3, & 2000, & \text { pp. } & \text { 237-247. }\end{array}$ http://dx.doi.org/10.1080/713678567

[24] L. Damschroder, D. Aron, R. Keith, S. Kirsh, J. Alexander, and J.Lowery, "Fostering implementation of health services research findings into practice: A consolidated framework for advancing implementation science", Implementation Science, vol. 4, 2009, p. 50.

[25] F.F. Nah, J.L. Lau, "Critical factors for successful implementation of enterprise systems", Business Process Management Journal, vol. 7, n. 3, 2001, pp. 286-296.

[26] A.C. Felstein, R.E. Glasgow, "A Practical, Robust Implementation and Sustainability Model (PRISM) for Integrating Research Findings into Practice", The Joint Commission Journal on Quality and Patient Safety, vol. 34, n. 4, 2008, pp. 228-243.

[27] J.H. Gittell, "New directions for relational coordination theory," in Oxford Handbook of Positive Organizational Scholarship, eds. K.S. Cameron and G. Spreitzer. Oxford University Press, 2011.

[28] S. Dopson, L. Fitzgerald, "The role of the middle manager in the implementation of evidence-based health care", Journal of Nursing Management, vol. 14, 2006, pp. 43-51. http://dx.doi.org/10.1111/j.1365-2934.2005.00612.x

[29] L.A. Palinkas, G.A. Aarons, B.F. Chorpita, K. Hoagwood, J. Landsverk, and J.R. Weisz, "Cultural exchange and the implementation of evidence-based practices: Two case studies", Research on Social Work Practice, vol. 19, n.5, 2009, pp. 602-612. http://dx.doi.org/10.1177/1049731509335529

[30] M.B. Pinto, J. K. Pinto, "Project team communication and crossfunctional cooperation in new program development", J. Product Innovation Management, vol. 7, 1990, pp. 200-212. http://dx.doi.org/10.1016/0737-6782(90)90004-X

[31] K. J. Gergen, Realities and relationships: Soundings in social construction. Cambridge, MA: Harvard University Press, 1994.

[32] L.R. Frey, "Group communication in context: Studies of natural groups". Hillsdale, NJ: Lawrence Erlbaum Associates, 1994.

[33] M.C. Balas, E.E. Vasilevskis, and W.J. Burke, "Critical Care Nurses' Role in Implementing the "ABCDE Bundle" Into Practice", Critical Care Nurse, vol. 32, 2012, pp. 35-47. http://dx.doi.org/10.4037/ccn2012229

[34] H.G. Gemuenden, T. Lechler, T, "Success factors of project management: The critical few. Reviewed paper", Portland Internat. Conf. Management of Eng. Tech. Portland, 1997, Oregon July 27-31.
[35] W. Stevenson, M.C. Gilly, "Problem solving networks in organizations: Intentional design and emergent structure". Social Sci. Res, vol. 22, 1993, pp. 92-113. http://dx.doi.org/10.1006/ssre.1993.1005

[36] S. Rubinstein "The impact of co-management on quality performance: The case of the Saturn Corporation", Indust. Labor Relations Rev. 53(1), 2000, pp. 197-220. http://dx.doi.org/10.2307/2696073

[37] M.J. Stevens, M.A. Campion," Staffing work teams: Development and validation of a selection test for teamwork setting", Journal of Management, vol. 25, 1999, pp. 207-228. http://dx.doi.org/10.1016/S0149-2063(99)80010-5

[38] S.E. Jackson, C.H. Chuang, E.E. Harden, and Y. Jiang, "Toward developing Human Resource Management systems for knowledge-intensive teamwork", Personnel and Human Resources Management, vol.15, 2006, pp.17-70.

[39] J.M. Bryson, P. Bromiley, "Critical Factors Affecting the Planning and Implementation of Major Projects", Strategic Management Journal, vol. 14, n. 5, 1993, pp. 319-337. http://dx.doi.org/10.1002/smj.4250140502

[40] Z. Huq, T.N. Martin, "Workforce Cultural Factors in TQM/CQI Implementation in Hospitals", Health Care Management Review, vol. 25, n. 3, 2000, pp. 80-93. http://dx.doi.org/10.1097/00004010200007000-00009

[41] D. Sanares, D. Heliker, "Implementation of an evidence-based nursing practice model: disciplined clinical inquiry", Journal of Nursing Staff Development, vol. 18, 2002, pp. 233-238. http://dx.doi.org/10.1097/00124645-200209000-00001

[42] A.J.R. Metz, and L. Bowie, L. Implementing evidence-based practices: Six "drivers" of success, Research-to-Results brief. Washington, DC: Child Trends, 2007.

\section{AUTHORS}

C. de Pablos Heredero is at the Rey Juan Carlos University, Madrid, Spain (Carmen.depablos@urjc.es).

S. Haider, is Assistant Professor at the Department of Management Sciences, COMSATS Institute of Information Technology, Vehari, Pakistan (sajidhaider@ciitvehari.edu.pk ).

A. García Martínez is at the Cordoba University, Cordoba, Spain (pa1gamaa@uco.es).

This article is an extended and modified version of a paper presented at the International GUIDE Conference, held at Universidad Panamericana, Guatemala, April 2014. Submitted 06 August 2014. Published as resubmitted by the authors 24 March 2015. 